\title{
Cutting-Edge Therapy Concepts - Cure Metastatic Breast Cancer?
}

\author{
Christoph Thomssen ${ }^{\mathrm{a}}$ Nadia Harbeck ${ }^{\mathrm{b}}$ \\ aUniversitätsklinik und Poliklinik für Gynäkologie, Martin-Luther-Universität, Halle/Saale, \\ 'Brustzentrum, Frauenklinik der Universität München, Germany
}

Current data from epidemiology shows that early breast cancer has become a curable disease. The mortality is declining substantially, less than $20 \%$ of patients diagnosed with breast cancer today will die from the disease [1-3]. Overall survival of $>90 \%$ seems feasible in operable breast cancer. Even the survival of patients with locally advanced disease has improved by more than $20 \%$ over the last 20 years. Fewer patients will experience metastases and it almost seems that metastatic breast cancer has stepped into the background. Consequently, we observe that less metastatic breast cancer patients than ever can be accrued for clinical trials.

Seeing so many optimistic results from early disease, it is quite understandable that patients, as well as their physicians, hope that also metastatic disease will become curable rather than merely well treatable. And sometimes they act as if it were already curable even without having sufficient evidence. Thus, the content of this issue of BrEast CARE is focused on interventions in metastatic breast cancer with a curative intent.

Is oligometastatic disease curable? Olivia Pagani and her colleague [4] discuss situations in which radical surgical or radiotherapeutical approaches to treat metastases may be applied with a curative intent. Some patients present with only a single or very few metastases. Quite understandably, they often ask to have them completely removed, surgically or by radiotherapy. The authors correctly state that unfortunately only retrospective data support such a procedure and apparently favorable results of 'radical' local therapy for limited metastatic disease may simply be the effect of a selection bias. Although in some patients such approaches may be helpful, this should not be generalized. The authors conclude that prospective clinical trials are required and that primary aims of such trials need to be carefully selected; moreover, maintaining quality of life and functional status may sometimes be more important than just small differences in survival. It is currently not clear, whether 'radical' local therapy for oligometastases is beneficial. Therefore, this approach should be confined to individual cases after thorough multidisciplinary discussion of the pros and cons. Is oligometastatic disease curable? It is resectable, but whether such a local approach substantially impacts on patient outcome we do not know!

Should we be more aggressive in primarily metastasized patients with regard to local therapy? Until recently, the oncology community had been influenced by the growing retrospective data pool concerning locoregional treatment in primary metastatic breast cancer. A meta-analysis of these data showed a more than doubled 3-year survival probability if the primary tumor was removed [5]. However, these apparently convincing data were contradicted by 2 prospective trials presented at the San Antonio Breast Cancer Symposium in December 2013. These data are presented and discussed by Steffi Hartmann and her colleagues [6] in this issue of BREAST CARE. Both prospective studies, well designed and fully recruited with an appropriate patient number, did not show any survival advantage by removing the primary tumor in stage IV disease. The authors also quote the caveats generated by older biological hypotheses: removing the primary tumor could even promote the growth of distant metastases, especially in women with multiple distant metastases [7]. They conclude that at the moment, breast surgery for these patients should not be offered as a routine practice outside clinical trials. The surgeon's scalpel may be ready to remove the tumor, however, this cut may be even shorten a patient's life!

Should we monitor palliative treatment more intensively? Standard monitoring comprises imaging including computed tomography and magnetic resonance tomography, and monitoring tumor markers, such as Ca 15-3 or CEA. Treatment for metastases normally is continued until response or resistance can be shown by shrinkage or growth of the metastases. However, serial detection of circulating tumor cells (CTC) could be a tool for better guiding potentially toxic therapies according to response prediction. Unfortunately, current evidence does not support a survival improvement in patients treated according to this model. Alunni-Fabbroni and colleagues [8] conclude that to date CTC should only be used within clinical studies. Thus, precision of medical treatment sometimes is not as easy as a knife's cut!

\section{KARGER}

Fax +497614520714

Information@Karger.com

www.karger.com (c) 2014 S. Karger GmbH, Freiburg

$1661-3791 / 14 / 0091-0005 \$ 39.50 / 0$

Accessible online at:

www.karger.com/brc
Prof. Dr. med. Christoph Thomssen

Klinik und Poliklinik für Gynäkologie

Martin-Luther-Universität Halle-Wittenberg

Ernst-Grube-Strasse 40, 06097 Halle/Saale, Germany

christoph.thomssen@medizin.uni-halle.de 
As shown above, there are more questions than answers in evidence-based treatment of patients with metastatic breast cancer. Thus, we appreciate and support the efforts that were undertaken to establish an international consensus conference on diagnosis and treatment of metastatic breast cancer (Advanced Breast Cancer Symposium in Lisbon ABC 2, 2013 [9]). There are still needs and new options for improving treatment in these patients.
In summary, in treatment of metastatic breast cancer, with our considerations and decisions we often teeter on a knife's edge. Yet, most frequently we need to admit that we can only achieve palliation, rarely we can realistically hope for cure. It is our responsibility to explain this realistic truth to our patients.

\section{References}

1 National Cancer Institute: http://seer.cancer.gov/ statfacts/html/breast.html (download 13.02.2014).

2 Robert-Koch-Institut, Zentrum für Krebsregisterdaten, http://www.krebsdaten.de/Krebs/DE/Content/ Krebsarten/Brustkrebs/brustkrebs_node.html (download 13.02.2014).

3 Tumorregister München. Überleben C50: Mammakarzinom (Frauen) [Internet]. 2013 [aktualisiert 01.04.2013]. Abrufbar von:

http://www.tumorregister-muenchen.de/facts/surv/ surv_C50f_G.pdf(download 13.02.2014)
4 Di Lascio S, Pagani O: Oligometastatic breast cancer: a shift from palliative to potentially curative treatment? Breast Care 2014;9: DOI: $10.1159 / 000358750$

5 Harris E, Barry M, Kell MR: Meta-analysis to determine if surgical resection of the primary tumour in the setting of stage IV breast cancer impacts on survival. Ann Surg Oncol. 2013;20:2828-2834.

6 Hartmann S, Reimer T, Gerber B, Stachs A: Primary Metastatic Breast Cancer: The impact of locoregional therapy. Breast Care 2014:9: DOI: $10.1159 / 000360054$
7 Fisher B, Gunduz N, Coyle J, Rudock C, Saffer E. Presence of a growth stimulating factor in serum following primary tumor removal in mice. Cancer Res 1989; 49: 1996-2001.

8 Alunni-Fabbroni M, Müller V, Fehm T, Janni W, Rack B: Monitoring in metastatic breast cancer: is imaging outdated in the era of circulating tumor cells? Breast Care 2014;9: DOI: 10.1159/000360438.

9 Thomssen C, Harbeck N: ABC2 Consensus Conference on Advanced Breast Cancer: brief summary of the consensus panel on Saturday November 9, 2013. Breast Care 2013;8:455-456. 